York and Chicago. A monument was erected to him in Vienna in 1908, when an address was delivered by his successor, Prof. Wagner von Jauregg.

\section{Palæozoic Coral Genera}

A complete list of the Palæozoic coral genera has been carefully prepared, correctly named, and supplemented by references to authors, synonyms, localities and published works ("Index of Palxozoic Coral Genera." By William Dickson Lang, Stanley Smith and Henry Dighton Thomas. Pp. vii +231 . London: British Museum (Natural History), 1940. 15s.). Genotypes are arranged in the alphabetical order of the trivial names, followed by the generic name and its author. In the list of literature it is useful to have a record of the genera described in each work. Dr. Lang presents the list as the foundation of future work on the phylogenetic classification of the corals. Although he examines critically the gradations and trends among Tabulate and Rugose corals, he and his collaborators leave the interpretation of the facts to others. The most laborious part of the task has, however, been performed for them. More than fifty generic names are pre-occupied by members of other phyla, and of the corals themselves, nearly twenty names are nomina nuda. This sifting and purifying should be of lasting benefit to workers on the group.

\section{Intelligence among Australian Aborigines}

THE difficulties of applying intelligence tests to primitive peoples with a view to comparative study are notorious, and much ingenuity has been emr loycd in devising tests which are immune from the vitiating factor of differences in the cultural background of the individuals or groups which it is sought to compare. The pioneer work of Dr. S. D. Porteous among Australian aborigines may be recalled in this connexion. Even more remarkable results, however, have been obtained by a recent expedition to the north-western regions of the Continent, sent out by the University of Western Australia, and consisting of three members of the Psychology Department, Mr. N. G. Trayten, Dr. D. W. McElwain and Dr. H. L. Fowler. Under the advice and with the cooperation of Dr. D. S. Davidson, assistant professor of anthropology in the University of Chicago, experiments were made in the application of intelligence tests which had not previously been tried with the Australian aborigines.

Not only was it desired to determine whether these tests were likely to prove more suitable for work with primitive peoples than those generally in use, but also whether they appeared to confirm the low estimate of aboriginal intelligence afforded by previous investigations. In a preliminary report on the work of the expedition, Dr. Fowler (Australian $J$. Ser., 2,$5 ; 1940$ ) records that, of the various tests applied experimentally, the Alexander Passalong test, involving the arrangement of coloured blocks in boxes, the Ferguson form koards, in which insets have to be placed in proper position, and the cube construction test, proved the most suitable, the second being the most satisfactory. Eighteen males and thirteen females were tested. They were of different ages, all but four being adults. In the results the interesting point lies not so much in the average mental age attained as in the range over which the scores spread, while considerable variation was noted in the different tribes. Still more remarkable is the fact that eight of the subjects in one test and five in another scored a mental age of fourteen or over, which indicates that they are at least at or above the level of the average white adult. From these results, which are in agreement with opin ons expressed by squatters as to aboriginal abilities, Dr. Fowler draws the conclusion that further investigations should be undertaken in order that, if these preliminary results are confirmed, steps may be taken to foster the development of such abilities.

\section{Roadwork and Bridges in Hungary}

Following its established custom, the municipal administration of Budapest has again called for tenders for dust-proofing the macadamized roads in the city. According to Roads and Road Construction of July, the proposal was to treat 522,000 sq. kilometres of roads with oil while the remaining 320,000 sq. kilometres of road requiring dust-proofing treatment would have been treated with tar. The bids proved that the price of oiling would have been one third higher than last year, while contractors also insisted on various disadvantageous clauses and conditions. The municipality has therefore decided to apply dust-proofing treatment to a total of $550,000 \mathrm{sq}$. kilometres of road surface only, using tar throughout. The Ministry of Commerce has issued a series of important commissions for the construction or reconstruction of roads and for two new bridges spanning the Danube and the Tisza respectively. The total commissions amount to well over seven million pengoes.

The new bridge over the Danube at Medve will cost more than two million pengoes, while that over the Tisza, in the Hungarian lowlands, will cost nearly 860,000 pengoes. The Danube bridge will be erected by the Hungarian Waggon and Machine Factory, while that on the Tisza will be built by Ganz and Company, of Budapest. The number of road contracts so far allotted is fourteen, and they have been awarded to the same number of different firms, partly to joint stock companies and partly to individuals. The majority of the roads will have concrete surfaces, although a few will have stone surfaces. The total amount of the fourteen orders is about 500,000 pengoes.

\section{Swiss Postal Railway}

IT is stated in the Bulletin of the Oerlikon Co. that an underground railway has recently been built in Zurich for the conveyance of letters and express packets between the branch post office at the main railway station and the Sihl post office, which are about three quarters of a mile apart. The railway is practically automatic. A driverless electric track is set in motion by pressing a push button on the main 